\title{
The Effect of Cigarette Smoking habits on the Outcome of Dental Implant Treatment
}

The aim of this study was to analyze the influence of smoking habits and other possibly relevant factors on dental implant survival. The study population included all patients who underwent dental implants between the years 1999-2008 at a large military dental clinic and were examined in the periodic medical examination center.

Correlation between implant characteristics and patients' smoking habits, as mentioned in the questionnaire answered by patients in the periodic examination, was performed.

Besides standard statistical methods, multiple linear regression models were constructed for estimation of the relative influence of some factors on implant survival rate. The long-term results of the implant treatment were good. The study refers to 7,680 implants. $7,359(95.8 \%)$ survived and $321(4.2 \%)$ did not survive. Concerning smoking habits, in a uni-variable analysis, factors found to have an association with implant survival were the smoking status of the patients (smoking/no smoking), the amount of smoking, passive smoking, and the time elapsed in ex-smokers from the time they ceased smoking to the time of implantation. In a multi-variable analysis, factors found to have an association with implant survival were smoking status (smoking/no smoking) and amounts of smoking as expressed in pack years. 
The Effect of Cigarette Smoking habits on the Outcome of Dental Implant Treatment

Dror Twito, Paul Sade

Department of Oral Rehabilitation, Medical Corps, IDF, Tel-Hashomer, Israel.

Short title: Smoking and Dental Implants

Key words: implant survival, implant failure, tobacco

\section{Corresponding author:}

Dr. Dror Twito

Department of Oral Rehabilitation,

Medical Corps, IDF,

Tel-Hashomer, Israel

Drortw99@gmail.com 


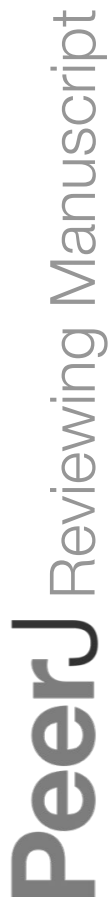

PeerJ reviewing PDF | (v2014:01:1337:2:1:ACCEPTED 6 Aug 2014) 


\section{Introduction}

2 The success and predictability of implants are well established. For a great

3 number of dental implant systems survival rates are within the 90 percentile . $4 \quad 1-9$

5 The success rates of implants tend to be lower than implant survival rates

6 and change in relation to the measured criteria (implant mobility, bone loss,

7 the presence of signs and symptoms, the resulting level of aesthetics,

8 etc.). Despite the fact that implant survival and success rates are high, there

9 is a growing impression that there are risk factors exposing patients to

10 complications and ultimately to failure of implants. Among the perceived

11 risks are occlusal overload, lower bone quality, and systemic diseases.

12 Smoking

13 A survey of health status in the United States has established a clear link

14 between smoking and low levels of periodontal health and support. ${ }^{10-11}$

15 Tobacco smoking reduces leukocyte activity and is responsible for a low

16 chemotactic migration rate, low mobility and low phagocytic activity. ${ }^{12}$ These

17 impairments cause low infection resistance and interrupted wound healing. ${ }^{12}$

18 Smoking is also related to low calcium absorption. ${ }^{12}$ Reports in the literature

19 show lower survivability of dental implants in smokers. ${ }^{13-15}$ One possible

20 mechanism by which smoking might affect osseointegration is lowering blood

21 flow rate due to increased peripheral resistance and platelet aggregation. ${ }^{16-17}$

22 Smoking by-products such as CO and cyanide delay wound healing and

23 together with nicotine inhibit cell proliferation. ${ }^{17}$ Tobacco directly affects

24 osteoblast function. ${ }^{17}$ Strietzel et al. (2007) performed a systematic review 
25 and meta-analysis including 35 studies in order to analyze whether smoking

26 affects implant prognosis with/without augmentations. ${ }^{18}$ In this review it was

27 reported that 5 retrospective studies and one prospective study showed a

28 relationship between smoking and inflammation around implants (peri-

29 implantitis). ${ }^{18}$ In 12 out of 13 studies there appeared to be significant

30 marginal bone absorption in smokers compared to non-smokers. ${ }^{18}$

31 Patients are usually advised to quit smoking at least two weeks before

32 implant surgery in order to allow recovery of normal blood viscosity and

33 platelet adhesion. Abstention from smoking should be extended at least 8

34 weeks after the implantation in order to permit the healing phase of the

35 osteoblasts to take place. ${ }^{20}$

36 The purpose of this research was to evaluate the relationship between

37 smoking habits and the amount of smoking on dental implant survival.

38 The null hypothesis is that there is no relationship between the amount of

39 smoking and implant survival.

40 Materials and methods

41 The retrospective study was based on a consecutive cohort of patients who

42 were treated by dental implants between the years 1999-2008 at a large

43 military dental clinic, and were examined in a periodic medical examination

44 center. No exclusion criteria applied. Two specialized oral and maxillofacial

45 surgeons placed all implants. All patients underwent periodic checkups in the

46 department of prosthodontics. Implant characteristics were recorded during

47 these checkups. In these checkups the implant status was defined either as 
48 survival or failure. Survival was defined when an implant was satisfactorily

49 functioning with no evidence of pain, suppuration, or inflammation.

50 Otherwise it was defined as failure. Data on smoking among the study

51 population is based on information gathered at the periodic medical

52 examination center which conducts examinations for military personnel. A

53 periodic medical examination is mandatory for the entire population of career

54 soldiers from the age of thirty. Those aged thirty to thirty-four are required to

55 perform the test once, from the age of thirty-five every three years, and

56 every two years from the age of fifty. Smoking is reported using a self-

57 administered questionnaire regarding health-related habits given as part of

58 the periodic examination.

59 Patients who visited the periodic medical examination center no longer than

60 a year before or after their implant placement were included in this study.

61 The following implant characteristics were recorded for those treated by

62 dental implant (table 1): implanted jaw, implanted region, immediate

63 implantation, bone augmentation in conjunction to implant placement, sinus

64 lift in conjunction to implant placement, membrane use, immediate loading,

65 implant failure. Based on the self-administered questionnaire, the following

66 smoking characteristics were recorded for those treated by dental implant

67 (table 2): smoking status, smoking years, number of cigarettes per day, pack

68 years (calculated by multiplying the number of packs of cigarettes smoked

69 per day by the number of years the person has smoked), past smokers-

70 number of cigarettes per day, past smokers- number of years without

71 smoking until implantation, exposure to passive smoking (the smoke of 
72 others) in closed places (home or at work) as qualitative data (exposure vs.

73 no exposure).

74 Correlation between implant characteristics and patients' smoking habits, as

75 mentioned in the questionnaire, was performed.

76 The Ethics Committee of the Israel Defense Force Medical Corps approved the 77 study.

78 Approval number: IDF - 879-2009.

79 Statistical analysis

80 Distributions of all the variables were tested. The relationship between each

81 of the variables and implant failures was analyzed using a Chi-Square test

82 and Fisher's exact test. The difference in age between the surviving and

83 failed implants was tested using a t-test. The correlation between smoking

84 and implant failure was also tested in regression logistic models and OR and

$8595 \% \mathrm{Cl}$ were calculated. Four models were built: two univariable and two

86 multi-variable models. In the uni-variable models, the dependent variable

87 was implant failure and the independent variable used was once smoking

88 status and once smoking groups by pack years. Multi-variable models were

89 built in order to test the association between smoking and implant failure

90 after neutralizing the effects of gender, age, type of loading, type and 
91 location of the implant. These variables were tested in the first block and

92 entered in the model by the Stepwise Forward Selection (Likelihood Ratio)

93 method with entry testing based on the significance of the score statistic, and

94 removal testing based on the probability of a likelihood-ratio statistic based

95 on the maximum partial likelihood estimates.

96 Entry $=0.05$, removal $=0.10$, maximum iterations 20 . The following smoking

97 variables: in the first model - smoking status and in the second model -

98 smoking groups by pack years, entered the second block model. 
99 Statistical significance was defined when $p \leq 0.05$. Data was analyzed using 100 the SAS and SPSS version 17 software. Results

101 The study population consisted of 9,706 implants performed between the 102 years 1999 and 2008. Information about smoking habits was available for 1037680 implants.

104 1. Implant properties:(table 1)

105 The study refers to 7,680 implants. 7,359 (95.8\%) survived and $321(4.2 \%)$ 106 did not survive. 6,731 implants (87.6\%) were placed in men and $949(12.4 \%)$ 107 in women. Patients' age ranged from 22-to 55 years, averaging 41.48 years, 108 with a standard deviation of 5.621 , and a median of 42 years.

109 2. Relationship between smoking habits and survivability of dental $110 \quad$ implants (table 2)

111 Implant failure rate was higher among smokers, 135 out of 2,406 (5.6\%), 112 compared to nonsmokers, 185 out of 5,259 (3.5\%), p<0.001. The figures show 113 a tendency to a higher failure rate with the increasing number of cigarettes 114 per day, 32 out of $752(4.3 \%)$ among smokers of 1-10 cigarettes a day and 115 up to 18 out of 195 (9.2\%) among those who smoked 31-40 cigarettes a day, $116 p=0.059$. There is a significant difference in relation to the number of 117 cigarettes smoked per day in present smokers, between failed implants 
118 among those who smoked up to 30 cigarettes a day compared to those who

119 smoked more than 30 cigarettes a day, $p=0.043$ (Figure 1).

120 A significant correlation was found between the implant failure rate and the

121 following variables: smoking years, exposure to passive smoking in

122 nonsmokers, smoking status and to the number of pack years (Figures 2-5.)

123 Correlation between implant survival and smoking in a uni- and multivariable

124 analysis

125 In order to test the link between smoking habits alone and implant

126 survival after neutralization of factors that were also found to have an

127 impact on implant survival, two indices representing the phenomenon

128 of smoking were selected: smoking status and pack years.

129

130

1. Smoking status

In the multivariable analysis presented in table 3 , it can be seen that

131 even after neutralizing the effect of other variables (type of loading,

132 type of implant rehabilitation and implanted jaw), present smoking

133 clearly increases the risk of implant failure $-\mathrm{P}=0.001 \mathrm{OR}=1.512$.

134

135

2. Pack years

1) The univariable analysis (table 4) shows that smoking over five pack

136 years increases significantly the chance of failure $(O R=1.659$ in

137 smokers of 5-10 pack years and $\mathrm{O} . \mathrm{R}=2.395$ in the group smoking

138 over 10 pack years) compared to non-smokers.

139

140

141

2) In a multi-variable analysis (table 5), after neutralizing variables such as immediate implantation, type of prosthesis and implanted jaw, it was found that in two groups, pack years between $5-10(0 . R=1.683$ ) 
143 increases significantly in relation to non-smokers.

\section{Discussion}

145 It is difficult to evaluate the role, importance and impact of one risk factor in

146 evaluating the results of treatment with implants. Chances are that there are

147 a number of factors affecting implant such as bone quality, location in the

148 mouth, type of prosthesis, para-functional habits, as well as systemic factors

149 such as smoking, osteoporosis, genetic factors and more. The reality is that a

150 large number of patients present a number of risk factors. The purpose of the

151 study was to evaluate the relationship between smoking habits and the

152 amount of smoking on dental implant survival. In relation to smoking habits,

153 in a uni-variable analysis, factors found to have an association with implant

154 survival are smoking status (smoking/no smoking), the amount of smoking,

155 passive smoking, and the time elapsed in past smokers from the time of

156 ceasing smoking to the time of implantation. In a multi-variable analysis,

157 factors found to be in association with implant survival are smoking status

158 (smoking/no smoking), and amount of smoking as expressed in pack years.

159 Other factors found associated with implant survival, in relation to implant

160 properties in a uni-variable analysis are immediate implantation, type of

161 prosthesis (fixed/removable) and implanted jaw. 
162 The significant difference found in relation to the type of prosthesis

163 (fixed/removable) between those failed and surviving implants is in harmony

164 with the literature. Based on an extensive literature review, Goodacre and

165 associates (2003) indicate that in both arches, implant failure is higher in a

166 removable prosthesis than on a fixed one. ${ }^{21}$

167 Concerning the failure rate of the two arches, this research indicates a larger

168 percentage of failures in the front of the mandible. Generally, but not

169 always, ${ }^{22}$ we find the failure rates to be higher in the maxilla. ${ }^{21,23}$ It is

170 possible that the reason for this higher rate of failure lies in the combination

171 of the type of bone and time of failure. Most of the failures in this study

172 occurred in the first year after implantation. There are reports in the literature

173 that show a link between early failures and D1 bone type. ${ }^{24}$ The highest

174 percentage of type D1-dense cortical bone is in the anterior mandible. This

175 bone type is made histologically from a dense lamellar calcified bone which

176 can stand high occlusal loading forces. However, this type of bone (D1) has

177 fewer blood vessels in relation to other types of bone and therefore is

178 dependent on the periosteum for the blood supply needed for healing the

179 bone after placing the implant. The cortical bone receives all external blood

180 supply in the outer external one-third of its width from the periosteum 25-26

181 and therefore requires a delicate and minimal reflection during surgery. The

182 various results linking smoking and the survival rate of implants correlates

183 well with the reports in the literature. ${ }^{13-15}$ Similar to this study, which found

184 more failures among smokers (5.6\%) compared to non-smokers (3.5\%),

185 Klokkevold and associates (2007) report, after a statistical analysis of 
186 fourteen studies that dealt with the topic of dental implant survival rates,

187 that the survival rate is lower by $2.68 \%$ in smokers than non-smokers.$^{27}$

188 After performing a meta-analysis of 21 studies, Hinode and associates (2006)

189 found that the risk of implant failure in smokers is higher significantly than

190 in non-smokers $-\mathrm{OR}=2.17$ in smokers versus $\mathrm{OR}=1.67$ in non- smokers. ${ }^{28}$

191 However, data referring to the amount or quantity of smoking (No. of

192 cigarettes or pack years) and its relation to implant survival rate is scarce.

193 Indeed, Klokkevold and associates (2007) conclude at the end of a statistical

194 analysis of 14 studies that an assessment of the relationship between the

195 level and amount of smoking and implant survival rate cannot be done. ${ }^{27}$

196 Indeed, Bain and associates (2003) indicate that moderate smoking (11-20

197 cigarettes a day) and heavy smoking (over 20 cigarettes) raise the risk of 198 implant failure ${ }^{29}$ but only in a machined implant surface. In this study, a

199 dose-related relationship between the amount of smoking and implant

200 survival rate was found. This relationship is expressed in the following

201 variables tested:

202 1) Number of cigarettes a day - in an analysis of uni-variables a

203 significant difference was found regarding the number of cigarettes a

204 day in present smokers. It turns out that smokers of over 30 cigarettes

205 a day have a bigger chance of failure, up to 1.6 greater than those who

206 smoke under 30 cigarettes a day.

207 2) Smoking years - present smokers who have smoked more than 10

208 years have a 1.7 times greater risk for implant failure than smokers

209 who have smoked less than 10 years. 
3) Pack years - the risk of failure rose significantly in 2 groups: the first, pack years of $5-10(O . R=1.68)$ and second, pack years greater than 10 $(O . R=2.296)$.

213 Another important issue in this study concerns passive smoking. A number

214 of studies indicate a link between passive smoking and cardiovascular

215 disease. ${ }^{30-32}$ Seemingly, an exposure to a mixture of toxins, chemicals, and

216 carcinogens react with different mechanisms in the body and cause vascular

217 damage, including endothelium inflammation, development of

218 arthrosclerosis, protein and cytokine changes as well as induced platelet

219 aggregation. Activities of the above mechanisms occurring alone or in

220 combination with each other, act synergistically to develop cardiovascular

221 diseases. $^{33 .}$ So far there is no reference in the literature to the relation

222 between passive smoking and implant failure. In this research a significant

223 correlation was found between exposure to passive smoking and implant

224 survival rate. The risk of implant failure among those exposed to passive

225 smoking is 2.3 times bigger than the risk of those who are not exposed to

226 passive smoking. This finding is in addition to the impact of passive smoking

227 on cardiovascular disease mentioned above. It is possible that the factors at

228 work are similar in both cases.

229 A correlation was found in this study between the number of years

230 intervening between the cessation of smoking and time of implantation in ex-

231 smokers, with a 2.7 times greater risk of implant failure in those who

232 underwent the implantation up to 2 years from the time of cessation of

233 smoking compared to those who had the implantation more than 2 years 
234 after the time of cessation. The reference in the literature to the protocol of

235 cessation of smoking before implantation is first made by Bain et al. (1996).

236 Bain and associates note a significant difference between implant failure in

237 those who followed the protocol in comparison to those who continued

238 smoking. ${ }^{34}$ The protocol rule is to stop smoking one week before and eight

239 weeks after placing the implants. This protocol is based on the medical

240 literature showing improvement in blood circulation after one week of

241 cessation of smoking and a histological proof of initial osseointegration taking

242 place in the first eight weeks after implantation. As evidenced by the data

243 arising from this study, it is possible that the survival rate rises as more time

244 passes from cessation of smoking to implantation beyond the week advised

245 by Bain's protocol.

246 This study has several limitations that should be taken into consideration

247 when evaluating the present results. First, using a retrospective cohort design

248 makes it difficult to control for all other factors, which might differ between

249 the different groups (smokers/non- smokers), passive smoking, and pack

250 years. These and other factors are known as confounding variables. We dealt

251 with this issue using the multi-variable models which were built in order to

252 test the association between smoking and implant failure after neutralizing

253 the effects of other variables (such as gender, age, type of loading, type and

254 location of the implant, etc.) In addition, our study is biased by the fact that

255 the subjects are a military population, which is a rather healthy population,

256 above a certain age and come to the periodic medical examination center

257 following army standing orders. Furthermore, relying on pre-existing self- 
258 reported data as we did in relying on the self-administered questionnaire,

259 limits the study in that the health-related habits are hard to verify

260 independently. With regard to information on passive smoking, it is important

261 to remark that although the data collected was of a qualitative nature

262 (exposure vs. no exposure) and did not give a quantitative indication to the

263 exposure to passive smoking in closed spaces, it allowed for the first time to

264 relate to this important variable. Finally, using the implant as the unit of

265 analysis, because of the nature of the data collection, makes it difficult to

266 adjust for effects of clustering of outcomes within patients. Applying a

267 different or more robust methodology might address the research problem

268 more effectively in any future study. Despite these limitations, the study

269 shows that after neutralizing the other variables, smoking status

270 (smokers/non- smokers), passive smoking, and pack years are the variables

271 relevant to implant survival.

\section{Conclusion}

273 The purpose of this research was to evaluate the relationship between

274 smoking habits and dental implant survival.

275 The main findings in this research are that smoking status (smokers/non-

276 smokers), passive smoking, and pack years are the variables found to be

277 relevant to implant survival after neutralizing other variables. Thus, the null

278 hypothesis was refuted. 
279 The clinical outcomes of this study are related to a number of aspects:

280 1. As patients, smokers and passive smokers must be informed of the

$281 \quad$ increased risk of failure.

282 2. Prevention - it is in the obligation of the clinician treating a patient to

283 guide and encourage the patient to cease smoking before undergoing

284 the procedure of implantation.

285 3. Treatment planning - the significant correlation found between

smoking 5-10 pack years and greater than 10 pack years in implant

287

failure should drive the clinician to search for alternative treatment

288 plans, not including implants, that would have better chances of

289 surviving in smoking patients. 


\section{REFERENCES}

1. Buser D, Mericske-Stern R, Bernard JP, Behneke A, Behneke N, Hirt HP, Belser UC, Lang NP. 1997. Long term evaluation of non- submerged ITI implants. Part 1 : 8-year life table analysis of a prospective multi-center study with 2359 implants. Clinical oral implants research ;8:161-172

2. Adell R, Eriksson B, Lekholm U, Branemark PI, Jemt T. 1990. Long-term follow-up study of osseointegrated implants in the treatment of totally edentulous jaws. The International journal of oral \& maxillofacial implants. ;5:347-359

3. Naert I, Koutsikakis G, Duyck J, Quirynen M,Jacobs R, van Steenberghe D. 2002. Biologic outcome of implant- supported restorations in the treatment of partial edentulism. Part 1 : A longitudinal clinical evaluation. Clinical oral implants research;13:381-389.

4. Vehemente VA, Chuang SK, Daher S, Muftu A, Dodson TB. 2002. Risk factors affecting dental implant survival. The Journal of oral implantology ; 28:74-81

5. Jemt T, Lekholm U, Adell R. Osseointegrated implants in the treatment of partially edentulous patients. 1989. A prelimanary study on 876 consecutively placed fixtures. The International journal of oral \& maxillofacial implants ;21-217.

6. Lindh T, Gunne J ,Tillberg A, Molin M. 1998. A meta - analysis of implants in partial edentulism. Clinical oral implants research; 9:80-90. 
7. Brocard D, Barthet P, Baysse E, et al. 2000. A multicenter report on 1022 consecutively placed ITI implants: A 7 year longitudinal study. The International journal of oral \& maxillofacial implants; 15:691-700.

8. Weibrich G, Budh RS, Wegner J, Wagner W. 2001. five-year prospective follow up report of the Astr tech standart dental implant in clinical treatment . The International journal of oral \& maxillofacial implants;16 : $557-562$.

9. Lekholm U,Gunne J, Henry P,et al. 1999. Survival of the Branemark implant in partially edentulous jaws: A 10 year prospective multicenter study. The International journal of oral \& maxillofacial implants; 14:639-645.

10. Ismail Al, Burt BA, Eklund SA. 1983. Epidemiologic patterns of smoking and periodontal disease in the United States. The Journal of the American Dental Association. May;106(5):617-21

11. Schenkein HA, Gunsolley JC, Koertge TE, Schenkein JG, Tew JG. 1995. Smoking and its effects on early-onset periodontitis. The Journal of the American Dental Association. Aug;126(8):1107-13.

12. Krall EA, Dawson-Hughes B. 1991.Smoking and bone loss among postmenopausal women. Journal of bone and mineral research. Apr;6(4):331-8.

13. Bain CA, Moy PK. 1993. The association between the failure of dental implants and cigarette smoking. The International journal of oral \& maxillofacial implants.;8(6):609-15 
14. Lambert PM, Morris HF, Ochi S. 2000. The influence of smoking on 3-year clinical success of osseointegrated dental implants. Annals of periodontology / the American Academy of Periodontology. Dec;5(1):79-89.

15. De Bruyn H, Collaert B. 1994. The effect of smoking on early implant failure. Clinical oral implants research. Dec;5(4):260-4

16. Herzberg R, Dolev E, Schwartz-Arad D. 2006. Implant marginal bone loss in maxillary sinus grafts. The International journal of oral \& maxillofacial implants. Jan-Feb;21(1):103-10

17. Levin L, Schwartz-Arad D. 2005. The effect of cigarette smoking on dental implants and related surgery. Implant Dentistry. Dec;14(4):357-61.

18. Strietzel FP, Kale A, Kulkarni M, Wegner B, Küchler I. 2007. Smoking interferes with the prognosis of dental implant treatment: a systematic review and meta-analysis. Journal of clinical periodontology. Jun;34(6):523$\underline{44}$

19. Heitz-Mayfield LJ. 2008. Peri-implant diseases: diagnosis and risk indicators. Journal of clinical periodontology. Sep;35(8 Suppl):292-304. Review

20. Bain CA, Moy PK. 1993. The association between the failure of dental implants and cigarette smoking. The International journal of oral \& maxillofacial implants.;8(6):609-15 
21. Goodacre CJ, Bernal G, Rungcharassaeng K, Kan JY. 2003. Clinical complications with implants and implant prostheses. The Journal of Prosthetic Dentistry. Aug;90(2):121-32.

22. Patrick D, Zosky J, Lubar R, Buchs A. 1989. Longitudinal clinical efficacy of Core-Vent dental implants: a five-year report. The Journal of oral implantology. 15(2):95-103.

23. Jemt T, Chai J, Harnett J, Heath MR, Hutton JE, Johns RB, McKenna S, McNamara DC, van Steenberghe D, Taylor R, Watson RM, Herrmann I. 1996. A 5-year prospective multicenter follow-up report on overdentures supported by osseointegrated implants. The International journal of oral \& maxillofacial implants. May-Jun;11(3):291-8.

24. Truhlar RS, Morris HF, Ochi S, Winkler S. 1994. Second-stage failures related to bone quality in patients receiving endosseous dental implants: DICRG Interim Report No. 7. Dental Implant Clinical Research Group. Implant Dentistry. Winter;3(4):252-5.

25. Chanavaz M. 1995. Anatomy and histophysiology of the periosteum: quantification of the periosteal blood supply to the adjacent bone with $85 \mathrm{Sr}$ and gamma spectrometry. The Journal of oral implantology. 21(3):214-9.

26. Vaughan JM. 1970. The physiology of bone, Oxford, Clarendon press.

27. Klokkevold PR, Han TJ. 2007. How do smoking, diabetes, and periodontitis affect outcomes of implant treatment? The International journal of oral \& maxillofacial implants.22 Suppl:173-202. 
28. Hinode D, Tanabe S, Yokoyama M, Fujisawa K, Yamauchi E, Miyamoto Y. 2006. Influence of smoking on osseointegrated implant failure: a metaanalysis. Clinical oral implants research. Aug;17(4):473-8.

29. Bain CA. 2003. Implant installation in the smoking patient. Periodontology 2000.33:185-93.

30. Kritz H, Schmid P, Sinzinger H. 1995. Passive smoking and cardiovascular risk. Archives of internal medicine. Oct 9;155(18):1942-8.

31. Barnoya J, Glantz SA. 2005. Cardiovascular effects of secondhand smoke: nearly as large as smoking. Circulation. May 24;111(20):2684-98.

32. Venn A, Britton J. 2007. Exposure to secondhand smoke and biomarkers of cardiovascular disease risk in never-smoking adults. Circulation. Feb 27;115(8):990-5. Epub 2007 Feb 12.

33. Vardavas Cl, Panagiotakos DB. 2009. The causal relationship between passive smoking and inflammation on the development of cardiovascular disease: a review of the evidence. Inflammation \& allergy drug targets. Dec;8(5):328-33.

34. Bain CA. 1996. Smoking and implant failure--benefits of a smoking cessation protocol. The International journal of oral \& maxillofacial implants. Nov-Dec;11(6):756-9. 


\section{Table $\mathbf{1}_{\text {(on next page) }}$}

Implant properties

을 Implant characteristics recorded for those treated by dental implant 
Table 1: Implant characteristics

$\begin{array}{ccccc}\text { P } & \text { Failed implants } & \text { TOTAL } & & \\ & (\%) \mathrm{N} & (\%) \mathrm{N} & & \\ 0.065 & (4.1) 316 & (99.3) 7628 & \text { NO } & \text { loading } \\ & & & & \\ & (9.6) 5 & \text { (0.7) } 52 & \text { YES }\end{array}$

$\begin{array}{llll}0.828 & \text { (4.2) } 296 & \text { (92.5) } 7106 \quad \text { Bone } & \text { augmentation }\end{array}$

(4.4)25 (7.5) $574 \quad$ YES

$\begin{array}{lcccc}0.857 & (4.2) 314 & (97.4) 7481 & \text { NO } & \text { Membrane use } \\ (3.5) 7 & \text { (2.6) } 199 & \text { YES } & \end{array}$

$0.007 \quad$ (3)95 (41.1) $3160 \quad$ MAXILA Implanted jaw

(4.6)174 (49) $3761 \quad$ MANDIBLE

(9.9) $759 \quad$ MISSING

INFORMATION

$\begin{array}{llccc}0.0001 & (4.0) 33 & (10.9) 834 & \text { MAX-front } & \text { Implanted region } \\ & (2.8) 50 & \text { (23.3) } 1788 & \text { MAX -premolar }\end{array}$




$\begin{array}{ccc}(2.2) 12 & (7.0) 538 & \text { MAX - molar } \\ (11.5) 46 & (5.2) 400 & \text { MAN-front } \\ (4.4) 43 & (12.6) 969 & \text { MAN - premolar } \\ (3.6) 85 & (31.1) 2392 & \text { MAN - molar } \\ & (9.9) 759 & \text { MISSING } \\ & & \text { INFORMATION }\end{array}$




\section{Table 2 (on next page)}

Relationship between smoking habits and survivability of dental implants

Implant failure rate was higher among smokers. There is a tendency to a higher failure rate with the increasing number of cigarettes per day. 
Table 2 . The relationship between smoking habits and implant survivability

\begin{tabular}{|c|c|c|c|c|}
\hline $\begin{array}{l}\text { Smoking } \\
\text { habit }\end{array}$ & & $\begin{array}{c}\frac{\text { Failed }}{\text { implants }} \\
\mathrm{N}(\%)\end{array}$ & $\begin{array}{c}\text { Surviving } \\
\frac{\text { implants }}{N(\%)}\end{array}$ & $p$ \\
\hline Smokers & $\begin{array}{l}\text { YES } \\
\text { NO }\end{array}$ & $\begin{array}{l}(5.6) 135 \\
(3.5) 185\end{array}$ & $\begin{array}{l}2271(94.4) \\
5074(96.5)\end{array}$ & 0.001 \\
\hline $\begin{array}{l}\text { Number of } \\
\text { cigarettes per } \\
\text { day }\end{array}$ & $1-10$ & $32(4.3)$ & $720(95.7)$ & 0.059 \\
\hline & $\begin{array}{l}11-20 \\
21-30 \\
31-40\end{array}$ & $\begin{array}{l}50(5.3) \\
34(6.9) \\
18(9.2)\end{array}$ & $\begin{array}{l}891(94.7) \\
462(93.1) \\
177(90.8)\end{array}$ & \\
\hline Smoking years & $\begin{array}{l}\text { Non- } \\
\text { smokers }\end{array}$ & $185(3.5)$ & $5074(96.5)$ & 0.001 \\
\hline & $\begin{array}{l}\text { Up to } 10 \\
\text { years }\end{array}$ & $14(3.5)$ & $384(96.5)$ & \\
\hline & $\begin{array}{l}\text { More than } \\
10 \text { years }\end{array}$ & $121(6)$ & $1887(94)$ & \\
\hline $\begin{array}{l}\text { Ex-smokers - } \\
\text { no. of } \\
\text { cigarettes per } \\
\text { day }\end{array}$ & $1-30$ & $40(2.8)$ & $1382(97.2)$ & 0.007 \\
\hline & $\begin{array}{l}\text { More than } \\
30\end{array}$ & $20(6.0)$ & $311(94.0)$ & \\
\hline $\begin{array}{l}\text { Ex-smokers - } \\
\text { no. of years } \\
\text { without } \\
\text { smoking until }\end{array}$ & $2-15$ & $31(2.3)$ & 1316(97.7) & 0.001 \\
\hline
\end{tabular}




\begin{tabular}{|c|c|c|c|c|}
\hline implantation & & & & \\
\hline \multirow[t]{2}{*}{$\begin{array}{l}\text { Exposure to } \\
\text { passive } \\
\text { smoking } \\
\text { (the smoke of } \\
\text { others) in } \\
\text { closed places }\end{array}$} & Yes & $(5) 39$ & $(95.0) 741$ & 0.001 \\
\hline & No & $(2.1) 21$ & $(97.9) 994$ & \\
\hline \multirow[t]{3}{*}{$\begin{array}{l}\text { Smoking } \\
\text { status }\end{array}$} & $\begin{array}{l}\text { Non } \\
\text { smokers }\end{array}$ & $(3.6) 125$ & $(96.4) 3334$ & 0.001 \\
\hline & $\begin{array}{l}\text { Past } \\
\text { smokers }\end{array}$ & $(3.3) 60$ & $(96.7) 1740$ & \\
\hline & $\begin{array}{l}\text { Present } \\
\text { smokers }\end{array}$ & (5.6)135 & $(94.4) 2271$ & \\
\hline \multirow[t]{5}{*}{ Pack years } & $\begin{array}{c}\text { Non- } \\
\text { smokers }\end{array}$ & $186(3.5)$ & $5088(96.5)$ & 0.001 \\
\hline & $X<=1$ & 15(3.6) & $399(96.4)$ & \\
\hline & $1<X<=5$ & $27(4.3)$ & $602(95.7)$ & \\
\hline & $5<x<=10$ & $41(5.7)$ & $676(94.3)$ & \\
\hline & $x>10$ & $52(8.0)$ & 594(92.0) & \\
\hline
\end{tabular}




\section{Table 3(on next page)}

Smoking status- multivariable analysis

after neutralizing the effect of other variables (type of loading, the type of implant and rehabilitation), present smoking clearly increases the risk of implant failure $\mathrm{P}=0.001 \mathrm{OR}=$ 1.512 . 
Table 3. Smoking status- multivariable analysis

\begin{tabular}{|c|c|c|c|}
\hline & OR & Cl 95\% & P \\
\hline $\begin{array}{c}\text { Non Immediate } \\
\text { implantation }\end{array}$ & 1 & & \\
\hline $\begin{array}{c}\text { Immediate } \\
\text { implantation }\end{array}$ & 3.104 & $1.179-8.171$ & 0.022 \\
\hline Fixed prosthesis & 1 & & \\
\hline $\begin{array}{c}\text { Removable } \\
\text { prosthesis }\end{array}$ & 2.212 & $1.219-4.015$ & 0.009 \\
\hline Maxilla & 1 & & \\
\hline Mandible & 1.636 & $1.264-2.119$ & $<0.001$ \\
\hline & & & \\
\hline & & & $\mathbf{P}$ \\
\hline Smoking status & 1 & $\underline{\text { Cl 95\% }}$ & \\
\hline Non smoker & 0.845 & $0.617-1.159$ & 0.297 \\
\hline Past smoker & 1.512 & $1.175-1.944$ & 0.001 \\
\hline Present smoker & & & \\
\hline
\end{tabular}

Age and gender were found to be not related to implant failure and therefore were not entered in the model 


\section{Table 4(on next page)}

Pack Year Uni- variable analysis

smoking over 5 Pack year increases significantly the chance of failure $(O . R=1.659$ in smokers 5-10 Pack Year and O. $R=2.395$ in the group smoking over 10 Pack Year) compared to non-smokers 
$\underline{\text { Table 4. Pack Year Uni- variable analysis }}$

\begin{tabular}{|c|c|c|c|}
\hline Pack Year & OR & Cl 95\% & $\mathrm{P}$ \\
\hline Non smokers & 1 & & \\
\hline $\mathrm{X}<=\mathbf{1}$ & 1.028 & $0.602-1.757$ & 0.918 \\
\hline $\mathrm{X}<=\mathbf{5}>\mathbf{1}$ & 1.227 & $0.812-1.853$ & 0.331 \\
\hline $\mathrm{X}<=\mathbf{1 0}>\mathbf{5}$ & 1.659 & $1.172-2.349$ & 0.004 \\
\hline $\mathbf{X}>\mathbf{1 0}$ & 2.395 & $1.741-3.294$ & $<0.001$ \\
\hline
\end{tabular}




\section{Table 5 (on next page)}

Pack Year Multi- variable analysis

In 2 groups, Pack Year between 5-10 (O. R = 1.683) and Pack Year greater than $10(\mathrm{O} . \mathrm{R}=$ 2.296) the risk of failure increases significantly in relation to non smokers 
$\underline{\text { Table 5. Pack Year Multi- variable analysis }}$

\begin{tabular}{|c|c|c|c|}
\hline & OR & Cl 95\% & P \\
\hline $\begin{array}{c}\text { Non Immediate } \\
\text { implantation }\end{array}$ & 1 & & 0.009 \\
\hline $\begin{array}{c}\text { Immediate } \\
\text { implantation }\end{array}$ & 3.649 & $1.383-9.630$ & \\
\hline Fixed prosthesis & 1 & & 0.20 \\
\hline $\begin{array}{c}\text { Removable } \\
\text { prosthesis }\end{array}$ & 2.035 & $1.120-3.698$ & \\
\hline & 1 & & \\
\hline Maxilla & 1.614 & $1.274-2.089$ & $<0.001$ \\
\hline Mandible & 1 & & \\
\hline Pack Year & 1.044 & $0.610-1.788$ & 0.875 \\
\hline Non smokers & 1.167 & $0.768-1.772$ & 0.470 \\
\hline $\mathbf{X < = 1}$ & 1.683 & $1.187-2.387$ & 0.003 \\
\hline $\mathbf{X < = 5 > 1}$ & 2.296 & $1.662-3.172$ & $<0.001$ \\
\hline$X<=10>5$ & & & \\
\hline $\mathbf{X}>\mathbf{1 0}$ & & & \\
\hline
\end{tabular}




\section{Figure 1}

Present smokers- failure percent by number of cigarettes

A significant difference in relation to the number of cigarettes a day, in present smokers, between failed implants, among those who smoke up to 30 cigarettes a day compared to those who smoke more than 30 cigarettes a day 

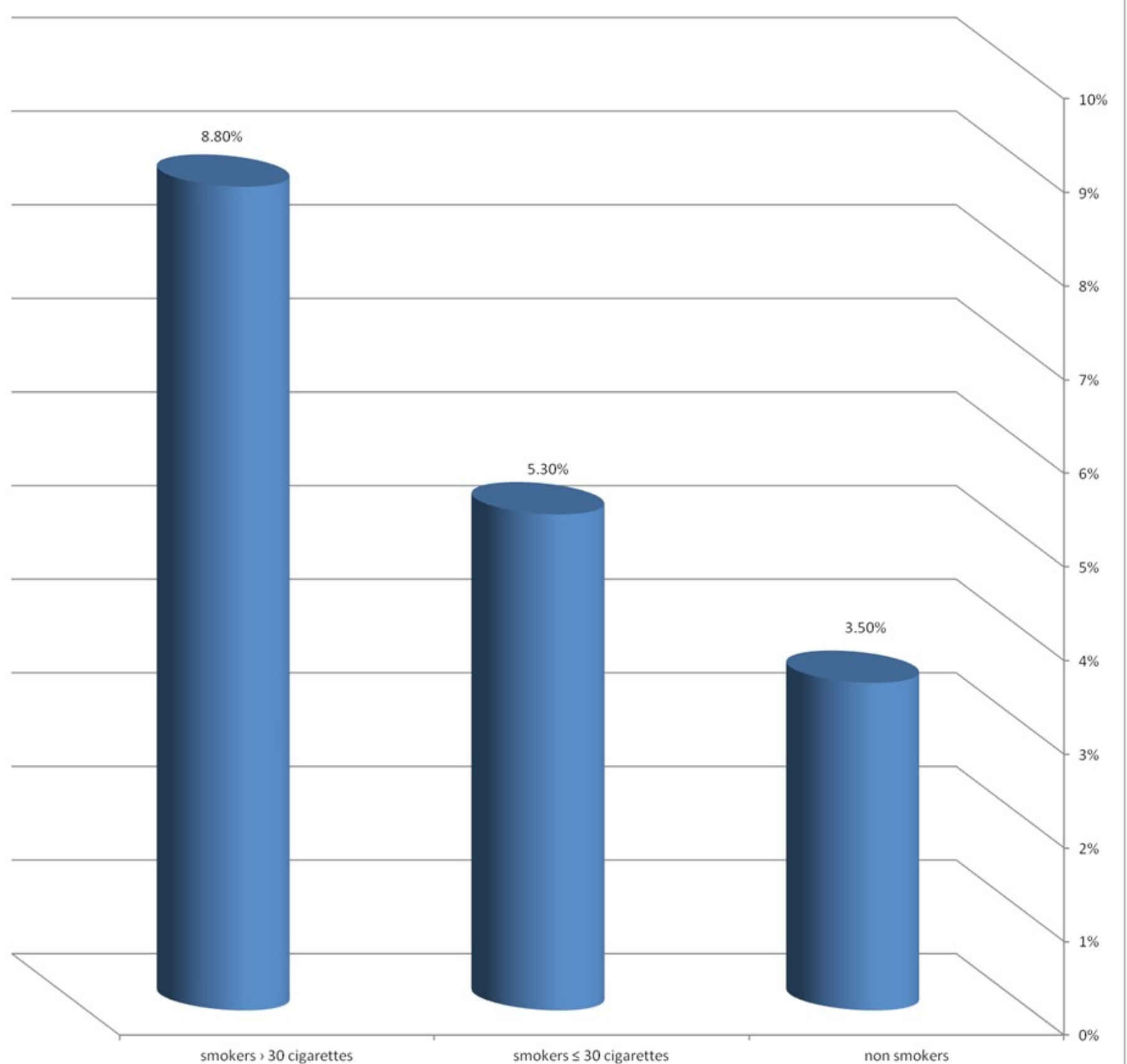


\section{Figure 2}

Present smokers- failure percent by years of smoking

Significant correlation was found between implant failure rate and years of smoking 


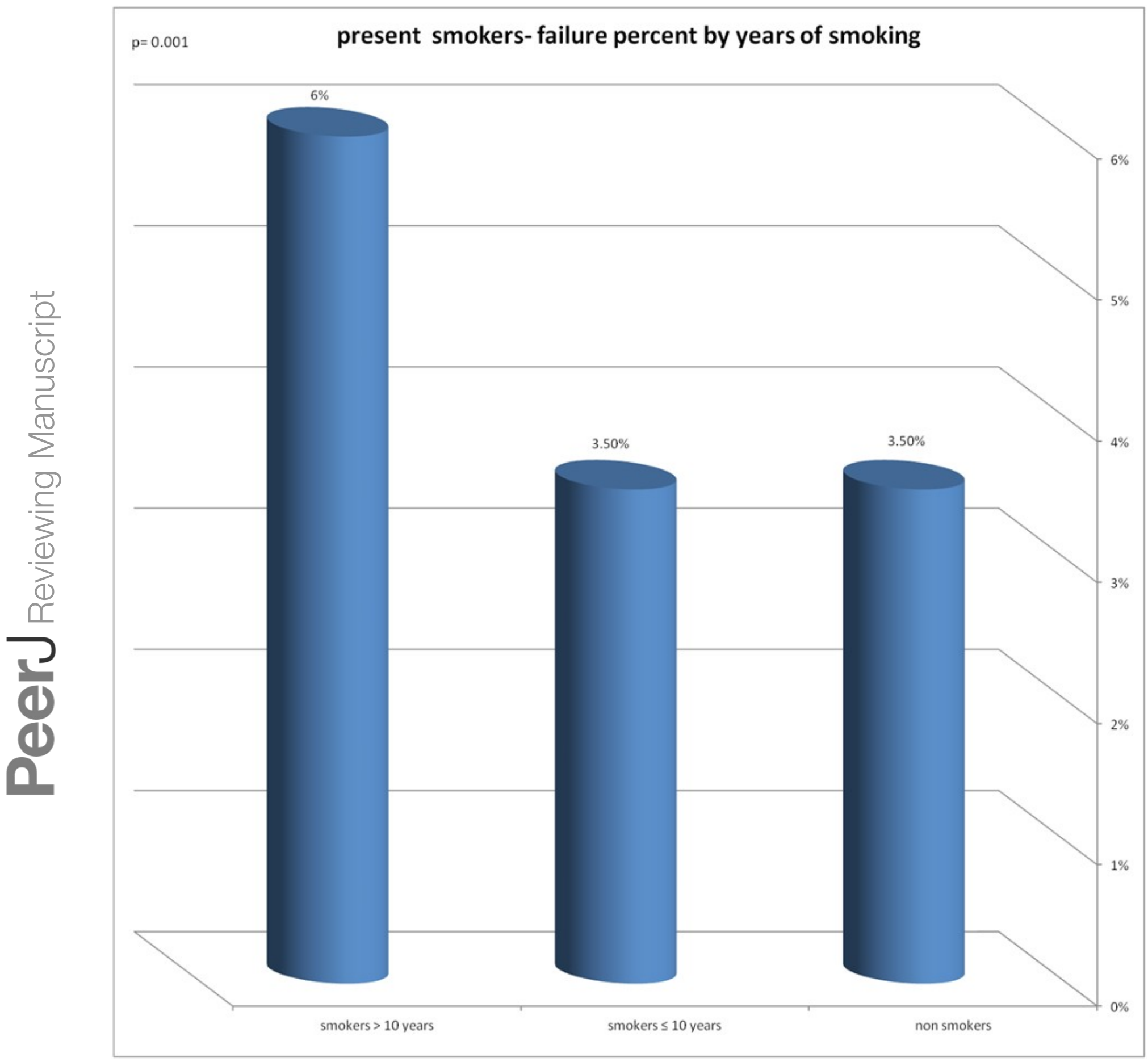




\section{Figure 3}

Failure percent in relation to passive smoking

Significant correlation was found between implant failure rate and exposure to passive smoking in non smokers 


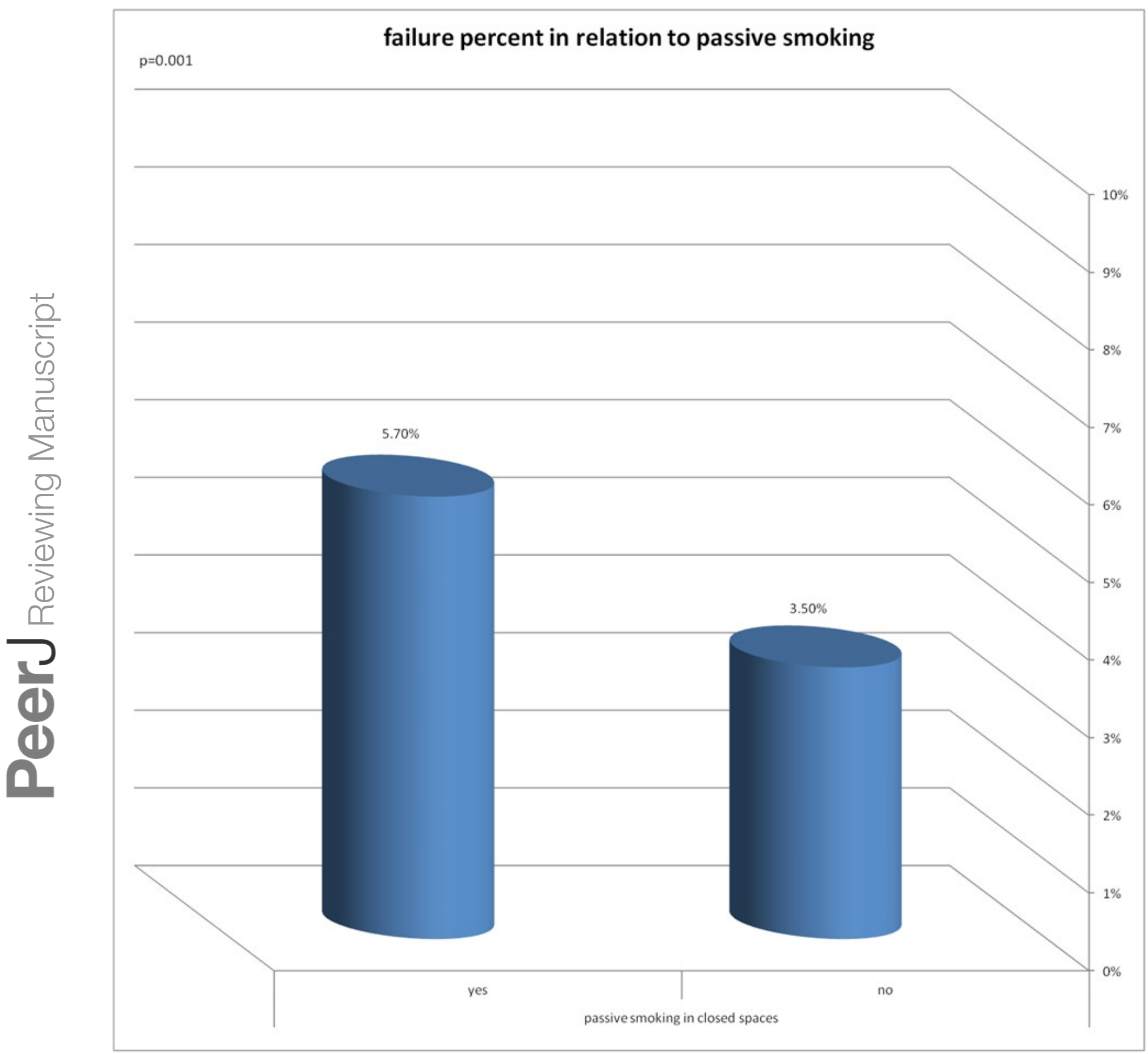




\section{Figure 4}

Failure percent by smoking status

Significant correlation was found between implant failure rate and smoking status 


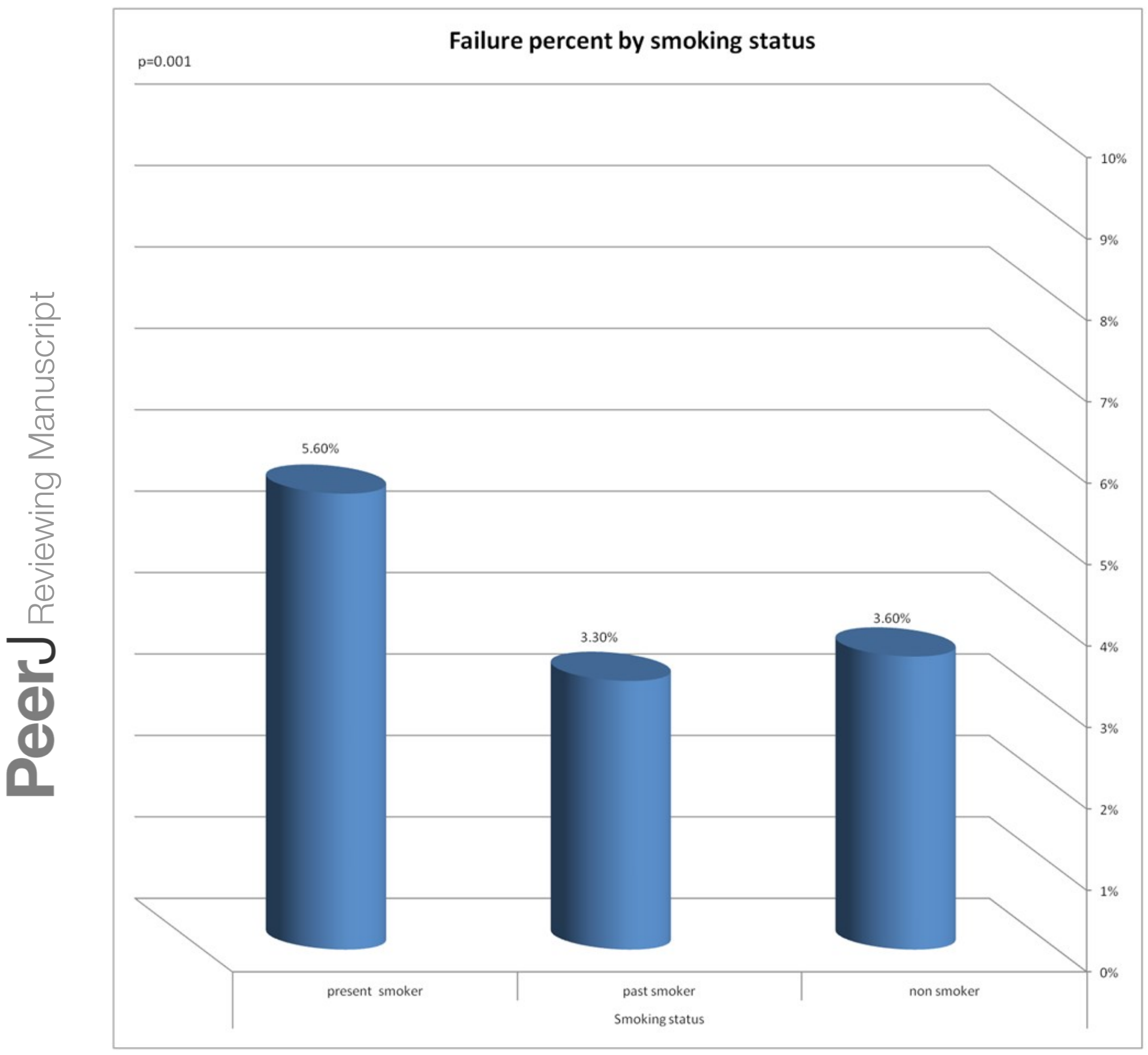




\section{Figure 5}

Present smokers - failure percent by Pack year

Significant correlation was found between implant failure rate and the number of Pack year 
- failure percent

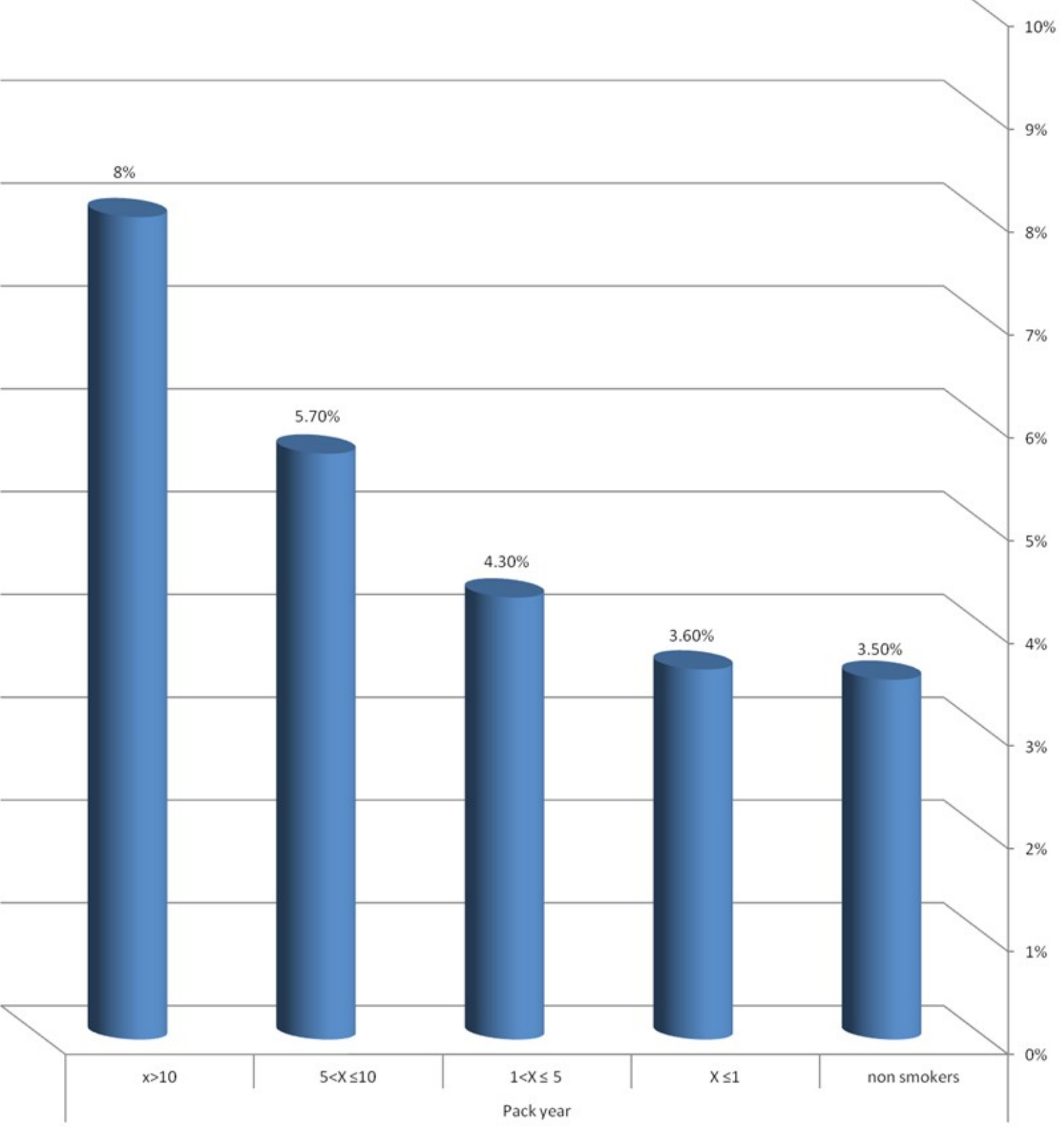

